\title{
Identifying salmon lice transmission characteristics between Faroese salmon farms
}

\author{
Tróndur J. Kragesteen ${ }^{1,2, *}$, Knud Simonsen ${ }^{1}$, André W. Visser ${ }^{2}$, Ken H. Andersen ${ }^{2}$ \\ ${ }^{1}$ Fiskaaling - Aquaculture Research Station of the Faroes, við Áir 11, FO430 Hvalvík, Faroe Islands \\ ${ }^{2}$ VKR Centre for Ocean Life, National Institute of Aquatic Resources, Technical University of Denmark, Building 202, \\ 2800 Kgs. Lyngby, Denmark
}

\begin{abstract}
Sea lice infestations are an increasing challenge in the ever-growing salmon aquaculture sector and cause large economic losses. The high salmon production in a small area creates a perfect habitat for parasites. Knowledge of how salmon lice planktonic larvae disperse and spread infection between farms is of vital importance in developing treatment management plans to combat salmon lice infestations. Using a particle-tracking model forced by tidal currents, we show that Faroese aquaculture farms form a complex network. In some cases as many as $10 \%$ of the infectious salmon lice released at one farm site enter a neighboring fjord containing another farm site. Farms were characterized as emitters, receivers or isolated, and we could identify 2 clusters of farms that were largely isolated from each other. These farm characteristics are a valuable input for the development of management plans for the entire Faroese salmon industry.
\end{abstract}

KEY WORDS: Connectivity $\cdot$ Dispersal $\cdot$ Tidal forcing $\cdot$ Particle tracking $\cdot$ Salmon lice

\section{INTRODUCTION}

In salmonid aquaculture, infestation with parasitic organisms is a major challenge and causes significant economic losses in the industry. The treatment costs are estimated to be around $€ 0.25 \mathrm{~kg}^{-1}$ (Costello 2009), and when applied to the global salmon production in 2015 of 2.3 million $t$ (FAO 2017), this translates to roughly $€ 575$ million. The estimated treatment cost per kg, although widely used, may be outdated (Shinn et al. 2015). In addition, the parasites impact the global aquaculture industry with negative publicity (Adams et al. 2015) due to the possible damage they have on the environment as a result of chemical treatments and influence on local wildlife (Ford \& Myers 2008). Consequently, salmon lice are a major obstacle in any further expansion of the salmon aquaculture industry.

As in other temperate coastal areas, the production of Atlantic salmon in the Faroe Islands has expanded to become a major activity. With an annual produc-

${ }^{*}$ Corresponding author: trondurk@fiskaaling.fo tion now exceeding 80000 tonnes $(\mathrm{t})$, the Faroe Islands is currently the fifth largest salmon producing country, and the aquaculture industry has become a major economic player locally as it accounted for $46 \%$ of the Faroese export value in 2016 (Statistics Faroe Islands [SFI] 2017). In 2014, the cost of drugs to combat sea lice used by the Faroese salmon farming industry exceeded $€ 18$ million, or roughly $€ 0.22 \mathrm{~kg}^{-1}$. Introduction of cleaner fish and mechanical treatments, however, reduced the expense of chemotherapeutants to less than $€ 13$ million in 2016 (SFI 2017).

Sea lice is a common name for a range of marine ectoparasitic copepods belonging to the family Caligidae. Two sea lice species cause by far the greatest challenge in salmonid aquaculture in the northern hemisphere: Lepeophtheirus salmonis and Caligus elongatus. L. salmonis is a parasite only found on salmonids, often referred to as salmon lice, while C. elongatus is a more opportunistic parasite, and has been found on 80 different fish species (Kabata 1979). Of the 2 species, L. salmonis has by far

(C) The authors 2018. Open Access under Creative Commons by Attribution Licence. Use, distribution and reproduction are unrestricted. Authors and original publication must be credited. 
the largest economic impact on the salmonid aquaculture industry due to its damaging effect on its host (Boxaspen 2006).

The increased salmon production has elevated the density of naturally occurring salmon lice in the water column, primarily due to the large growth in the number of hosts. The high density further increases the chances of salmon lice being transmitted between hydrodynamically connected farms. Additionally, experience shows that sporadic uncontrolled treatment of salmon lice in an area yields a resistant salmon lice population over time (Murray 2011, Aaen et al. 2015). Farms with intense treatment might quickly develop resistant salmon lice strains. In inter-connected farm networks, the resistant strains spread out to the whole network after a given period. Therefore, in connected farm networks, there may be a point when the external infection pressure reaches a stage when, from a farmers perspective, treatment becomes virtually pointless. Coordinated treatment management plans are thus essential to achieve long-term sustainable control of salmon lice. Achieving control requires a thorough understanding of the sea lice dispersion patterns, a factor highly dependent on regional and local hydrography (Adams et al. 2015).

Dispersion of salmon lice larvae has been studied using numerical models in Scotland (Amundrud \& Murray 2009, Adams et al. 2012, 2015, Salama et al. 2013), Canada (Stucchi et al. 2011), and Norway (Asplin et al. 2014, Johnsen et al. 2014, 2016, Samsing et al. 2017). For a more comprehensive overview, see Salama \& Rabe (2013). In some fjord systems, farms were found to be inter-connected (Adams et al. 2012, Johnsen et al. 2016), while in other cases several clusters of connected farms could be identified (Salama et al. 2013, in press). Samsing et al. (2017) investigated the connectivity between most farms on the Norwegian coast and found that seasonal variations influence the connectivity. These cases need different management strategies, emphasizing the importance of knowing the specific farm network. This study presents a first attempt to investigate the dispersion of salmon lice and connectivity between aquaculture farms in the Faroe Islands. While earlier studies have either been on farms located in a restricted area mainly enclosed by land (Adams et al. 2012, Salama et al. 2013, in press) or along a long coast with complicated fjord systems (Stucchi et al. 2011, Asplin et al. 2014, Johnsen et al. 2014, 2016, Samsing et al. 2017), this study is of a spatially limited archipelago with a relatively high farm density in a tidally energetic area surrounded by open ocean.
The limited number of farms in a nearly isolated system makes the Faroe Islands an ideal area to investigate the interaction and population dynamics of salmon lice.

\section{METHODS}

\section{Study area}

The Faroe Islands are an archipelago in the Atlantic ocean containing complicated coastlines, multiple fjords, and connecting straits (Fig. 1). The distance from the northernmost to the southernmost point is about $110 \mathrm{~km}$. Due to their location in the path of the North Atlantic Current, the sea around the Faroe Islands is dominated by relatively warm and saline waters with fairly stable conditions. The temperature varies from $6^{\circ} \mathrm{C}$ in February to approximately $10^{\circ} \mathrm{C}$ in August and September, and the variation in salinity is confined to 35.05 to $35.25 \%$ on the shelf (Larsen et al. 2008, Gaard et al. 2011) but reduces towards 32\%o in the fjords due to freshwater runoff (Gaard et al. 2011)

The waters on the Faroe Shelf can be characterized as a tidal energetic system, although the tidal elevation amplitude is quite modest. The amplitude of the dominating $M_{2}$-constituent varies from some $60 \mathrm{~cm}$ in the westernmost islands to less than $10 \mathrm{~cm}$ at the central eastern coast (Simonsen \& Niclasen 2011), which may be characterized as a semi-amphidromic point. This relatively large gradient towards the central east coast creates strong currents with maximum speeds of up to $3.6 \mathrm{~m} \mathrm{~s}^{-1}$ (Fig. 1) in some straits (Larsen et al. 2008, Simonsen \& Niclasen 2011). Further, Larsen et al. (2008) have shown that the tides, through rectification, are the main driver of a steady current clockwise around the islands (Fig. 2).

In some of the fjords, and in the strait between the 2 biggest islands (white arrowhead, Fig. 1), the tides have less influence on the circulation (Fig. 1) and stratification may occur mainly due to the freshwater runoff (Gaard et al. 2011). In these areas, estuarine- and wind-driven circulation is of significant importance.

Outside the fjords, however, the water masses are quite homogeneous due to the intense mixing caused mainly by tidal currents (Larsen et al. 2008). We therefore focus on the tidal component in the model due to the dominating influence it has on water movement around the Faroe Islands. Including only the tidal component simplifies the model, but still reveals the general background dispersion pattern. 


\section{Model overview}

The underlying tidal circulation model is an implementation of the barotropic mode of the regional oceanic modeling system (ROMS) (Shchepetkin \& McWilliams 2005) on a half nautical mile grid resolution covering a larger area, and on a $100 \mathrm{~m}$ resolution grid for the coastal region (Simonsen \& Niclasen 2011). The higher resolution model was forced by the solution from a coarser model, which applied altimetric data generated by Egbert et al. (1994) along its open sea boundaries. After a spin-up period, data were stored at $1 \mathrm{~h}$ intervals for every grid point over $30 \mathrm{~d}$ for tidal analysis using the T_TIDE software (Pawlowicz et al. 2002). Validation of the derived harmonic constants towards similar data derived from observed time series from tidal gauges and current measurement showed general good agreement (Simonsen \& Niclasen 2011). Here the current is estimated from the dominating constituents and the residual current obtained from the $100 \mathrm{~m}$ resolution tidal model.

\section{Tidal current}

We included 3 semi-diurnal constituents, $M_{2}, S_{2}$ and $N_{2}, 2$ diurnal constituents, $K_{1}$ and $O_{1}, 1$ over-tide constituent, $M_{4}$, and the residual current. The east $(u)$ and north $(v)$ components of the forcing current at a given time $(t)$ are obtained by summing up the contribution from the $6(n)$ tidal constituents and residual current $\left(u_{r}, V_{r}\right)$ at each horizontal position $(x, y)$ :

$$
\begin{aligned}
& u(t, x, y)=u_{r}(x, y)+\sum_{i}{ }^{n} a_{i}(x, y) \cos \left(\omega_{i} t-\right. \\
& \varphi(x, y)) \cos (\theta(x, y))-b_{i}(x, y) \sin \left(\omega_{i} t-\varphi(x, y)\right) \sin (\theta(x, y)) \\
& v(t, x, y)=v_{r}(x, y)+\sum_{i}{ }^{n} a_{i}(x, y) \cos \left(\omega_{i} t-\varphi(x, y)\right) \sin (\theta(x, y)) \\
& -b_{i}(x, y) \sin \left(\omega_{i} t-\varphi(x, y)\right) \cos (\theta(x, y)) \\
& \omega_{i} t=2 \frac{\pi}{T_{i}} t
\end{aligned}
$$

where $\varphi_{i}$ is the Greenwich phase $\operatorname{lag}, \theta_{i}$ the inclination and $a_{i}$ and $b_{i}$ are the major and minor semi-axis, respectively, defining the tidal ellipse at a given geographical location of the $i$ th constituent with frequency $\omega_{i}(t)$ and corresponding period $T_{i}$.

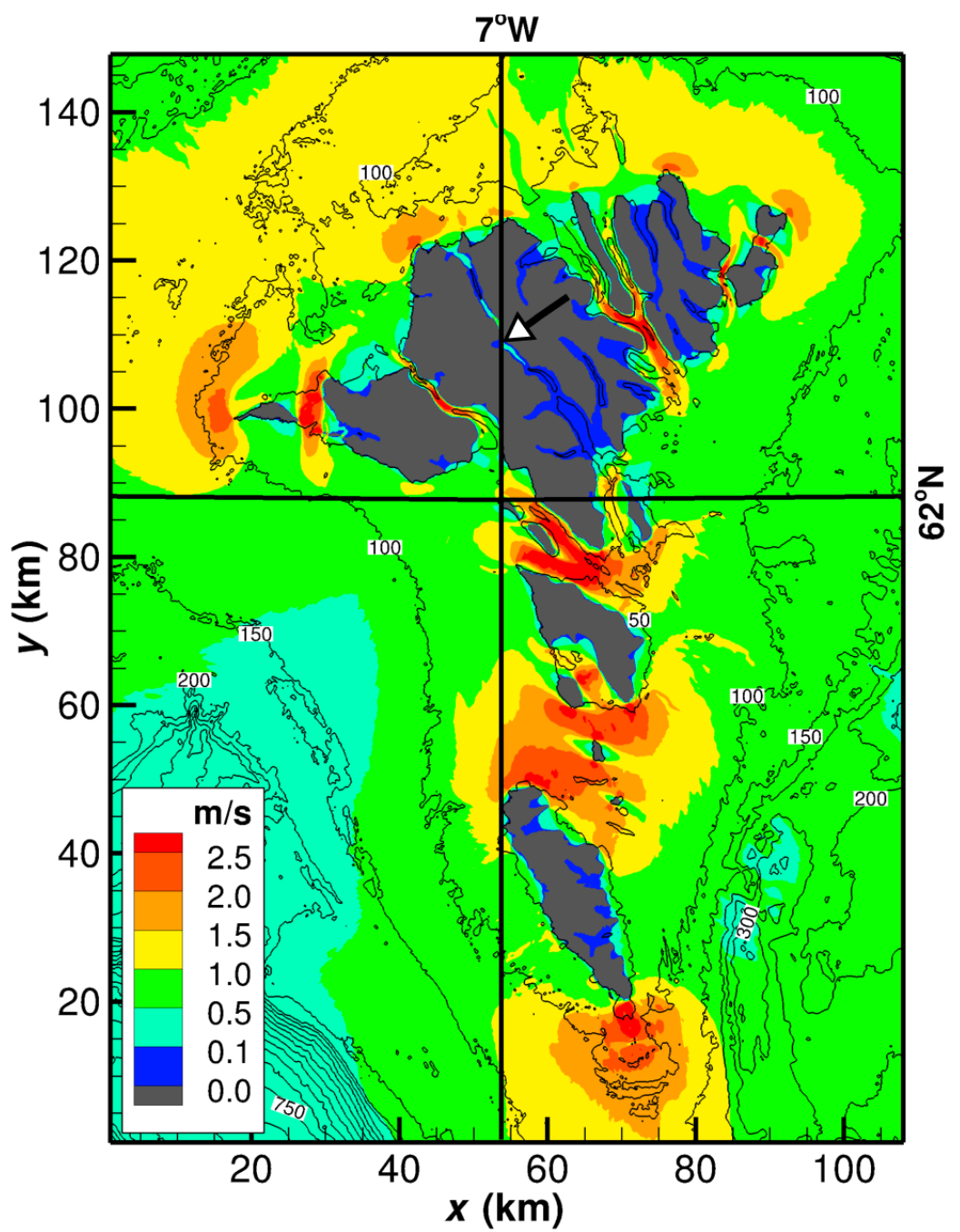

Fig. 1. Maximum tidal current velocity around the Faroe Islands provided as the sum of the semi-major axes of the 6 dominating constituents (Simonsen \& Niclasen 2011). Thin contour lines provide the water depth (m). The white arrow indicates the location of the large narrow strait

\section{Particle-tracking model}

Salmon lice are represented as passive particles, each representing an arbitrary but uniform number of salmon lice. Because the tidal current model is barotropic, the current is assumed to be vertically uniform, and the vertical movement of the salmon lice is omitted. Turbulent diffusion is included with a horizontal random walk component (Visser 1997). The trajectories of each particle is calculated with an Euler scheme where the position $(x, y)$ of particle $q$ at the next time step, $t+\Delta t$, is calculated from the velocity, $u$ and $v$ :

$$
\begin{aligned}
& x_{q}(t+\Delta t)=x_{q}(t)+u(x, y, t) \Delta t+R \sqrt{6 D_{h} \Delta t} \\
& y_{q}(t+\Delta t)=y_{q}(t)+v(x, y, t) \Delta t+R \sqrt{6 D_{h} \Delta t}
\end{aligned}
$$

where $R$ is a uniformly distributed random number within $[-1,1] . D_{h}$ is the diffusion coefficient and is set 


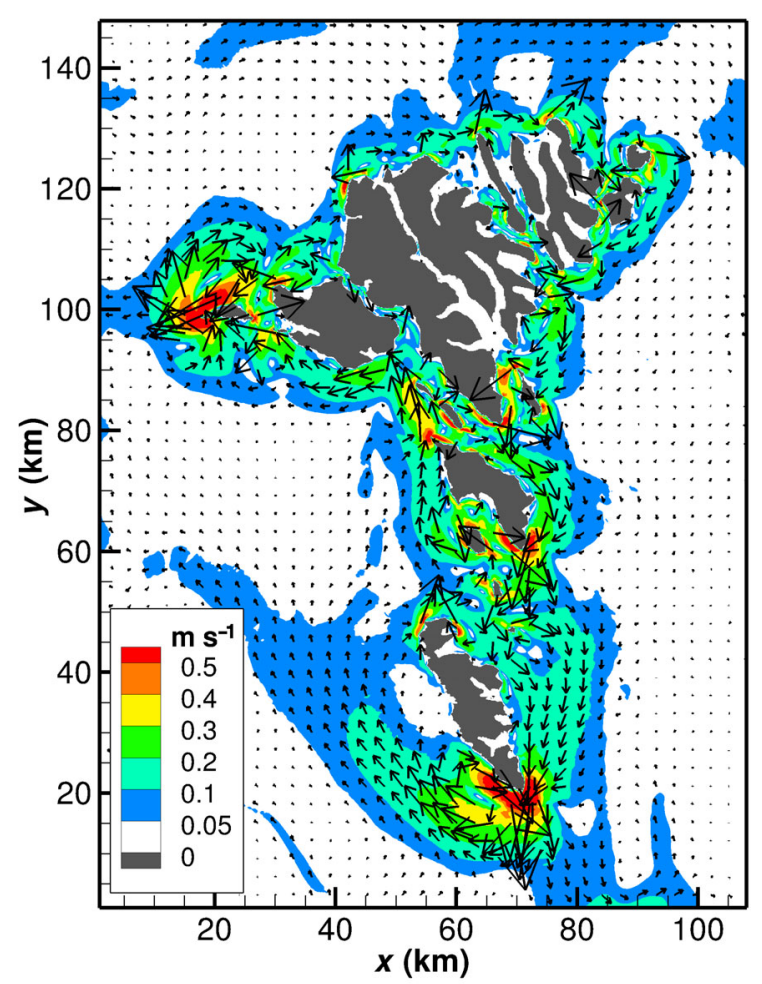

Fig. 2. Residual tidal current velocity around the Faroe Islands. The vectors indicate the direction, and the colors indicate the speed (Simonsen \& Niclasen 2011)

to $0.1 \mathrm{~m}^{2} \mathrm{~s}^{-1}$ (Gillibrand \& Willis 2007). The computationally cheap and easily implemented Euler scheme was chosen instead of a more accurate higher order scheme. This loss of numerical accuracy is justified by the inclusion of the turbulent diffusion term, which anyway leads to diffusion. A sensitivity analysis of the time step was conducted (not shown) and satisfying convergence was obtained with a time step of $0.005 \mathrm{~h}$ (18 s), which is used in the present simulations. Particles crossing the outer boundary are considered lost and removed from the simulation. A no flux reflective boundary condition is applied at the shoreline (Brickman et al. 2009). For the particle-tracking simulation, the $100 \mathrm{~m}$ resolution grid of the tidal model was adopted. The number of particles released was tested and the mean trajectory of the particle cluster between identical simulations was found to be reasonably converged when releasing 900 particles every hour.

\section{Biological parameters}

When modeling the dispersion of salmon lice, the 3 non-feeding planktonic stages, nauplii I, nauplii II, and copepodid, are relevant. The non-infectious Lep- eophtheirus salmonis nauplii larvae hatch from the adult female egg strings and are released into the planktonic environment where they molt into a second nauplii stage and further into the infectious copepodid larvae (Pike \& Wadsworth 1999). Being non-feeding, the planktonic larvae have only the energy from their internal yolk reserves for survival and therefore need to locate and infect a host within a limited lifespan. Infection of a new host is determined by the survival of the larvae and the likelihood of infectious larvae making contact with a new host. The infection rate is a function of attachment success, water currents, temperature, salinity, grazing, etc.

In our model, salmon lice larva biology is represented by 3 processes: duration of the nauplii and copepodid stages, and mortality. The development time of the planktonic phases are primarily determined by the water temperature when salinity is above $30 \%$ (Samsing et al. 2016). Here, we assume a summer scenario with a sea temperature of $10^{\circ} \mathrm{C}$. The duration and longevity of these first phases decrease with increasing temperature. Both Johnson \& Albright (1991) and Samsing et al. (2016) found a similar development time for $L$. salmonis nauplii, which require approximately $3.7 \mathrm{~d}$ to develop into an infectious copepodid at $10^{\circ} \mathrm{C}$. The longevity of the copepodid at the same temperature is approximately 13 d (Gravil 1996, Samsing et al. 2016).

Determining mortality is more difficult because studies of $L$. salmonis larvae in their natural environment are scarce. Stien et al. (2005) studied population dynamics of $L$. salmonis and estimated the mortality rates of nauplii and copepodids to be approximately 0.17 and $0.22 \mathrm{~d}^{-1}$, respectively, based on laboratory experiments. The survival probability over time is:

$$
p(t)=e^{-\mu t}
$$

where $p$ is the survival probability at time $t$. Mortality $(\mu)$ is assumed to be $0.17 \mathrm{~d}^{-1}$ for both planktonic phases.

Nauplii and copepodid larvae have been shown to be phototactic and to have the ability to migrate away from low salinity and seek higher temperatures in the upper layers (Johnsen et al. 2014, 2016, á Norði et al. 2015). Gillibrand \& Willis (2007) and Johnsen et al. (2014) showed that relatively small vertical movement behaviors had a significant effect on the dispersion pattern in stratified waters, emphasizing the need for a more comprehensive model in estuarine-driven areas. However, outside the Faroese fjords, where the circulation is dominated by the tides (Larsen et al. 2008), the connectivity between the salmon farming locations will those also be dominated by tides. 


\section{Simulations and connectivity matrices}

Based on the existing farm locations as listed by the authorities, 24 farm sites were defined, to each of which a receiving and an emitting area were assigned (Fig. 3). The emitting area corresponds to the actual farm site locations. In those cases where several farms are located in a fjord, only the farm site closest to the fjord opening is included (Fig. 3). The model is barotropic, and thus no attempt is made to simulate the estuarine circulation which may appear in fjords with little tidal influence (Fig. 1). The neglected estuarine circulation is, however, of importance for the dispersion within these fjords, and consequently the receiving farm area (or 'hit area') is subjectively defined as the entire fjord if the farm is located inside a fjord or the long narrow strait between the 2 largest islands (Fig. 3). A copepodid larva entering these areas is considered an infection risk to the whole area. Farms located in more open and tidal-dominated areas (Farms 5, 9, and 13; Fig. 3) are assigned a receiving area which corresponds to the farming site. This is different from other connectivity studies where a fixed area around the farm is considered to pose an infectious risk to the farm

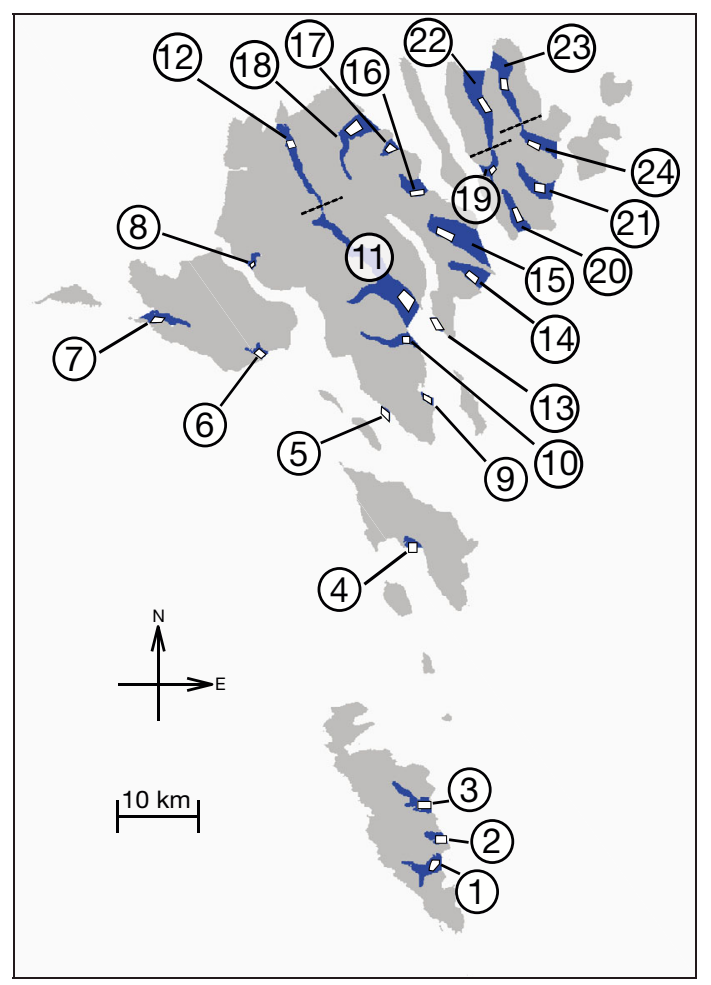

Fig. 3. Farm areas (blue) and lice release sites (white polygons). Dashed lines distinguish 2 farm areas from each other. There is water connection between Farm areas 11 and 12, but not between 19 and 22, and 23 and 24 ranging from a $500 \mathrm{~m}$ radius (Adams et al. 2012, Salama et al. in press) to a $600 \times 600 \mathrm{~m}$ (Johnsen et al. 2016) and $800 \times 800 \mathrm{~m}$ area around the farm (Samsing et al. 2017).

The connectivity matrices were generated by releasing 900 particles every hour from each defined farm site emitting area (1.8 million particles) over a period of $2000 \mathrm{~h}(83.3 \mathrm{~d})$. The simulation period includes several spring-neap tide cycles and gives the system sufficient time to converge and therefore reflects a long-term dispersion trend. All farms are evenly weighted assuming this is a linear process and therefore the exact number of salmon lice a particle represents becomes irrelevant in this context. We adopted a similar approach to that described by Adams et al. (2012), where particles can infect any farm, including the initial release farm, when they are older than $3.7 \mathrm{~d}$. Further, the particles have an infection window of $13 \mathrm{~d}$, assuming a typical Faroese summer scenario with a water temperature of $10^{\circ} \mathrm{C}$. A particle is only allowed to infect a given farm site once, meaning that if they re-enter the same farm site, the particles are not recorded. However, the particle is allowed to continue in the simulation and potentially infect a new farm site, which is different from Adams et al. (2012), where particles were taken out of the simulation when the first connection was made. Particles are taken out of the simulation when they become older than $16.7 \mathrm{~d}$. The connection probability between 2 farms is calculated as the ratio between infectious particles entering one farm's receiving area from another farm and the total amount of released particles from the emitting farm. The average age of the infectious particles in a connection is estimated using their age at their entry into a receiving area. The connection probability between 2 farms including mortality is found by weighting the infectious particles with the survival probability using Eq. (6).

\section{RESULTS}

\section{Dispersion}

Examples of particle dispersion patterns are illustrated in dispersion maps showing the mean age over the simulation period of particles released from Farms 2, 5, and 21 (Fig. 4) in every $100 \times 100 \mathrm{~m}$ grid cell. The 3 locations were chosen by their geographic location and position in relatively exposed tidal areas, which allows larvae to escape their initial release site, but at different rates. 

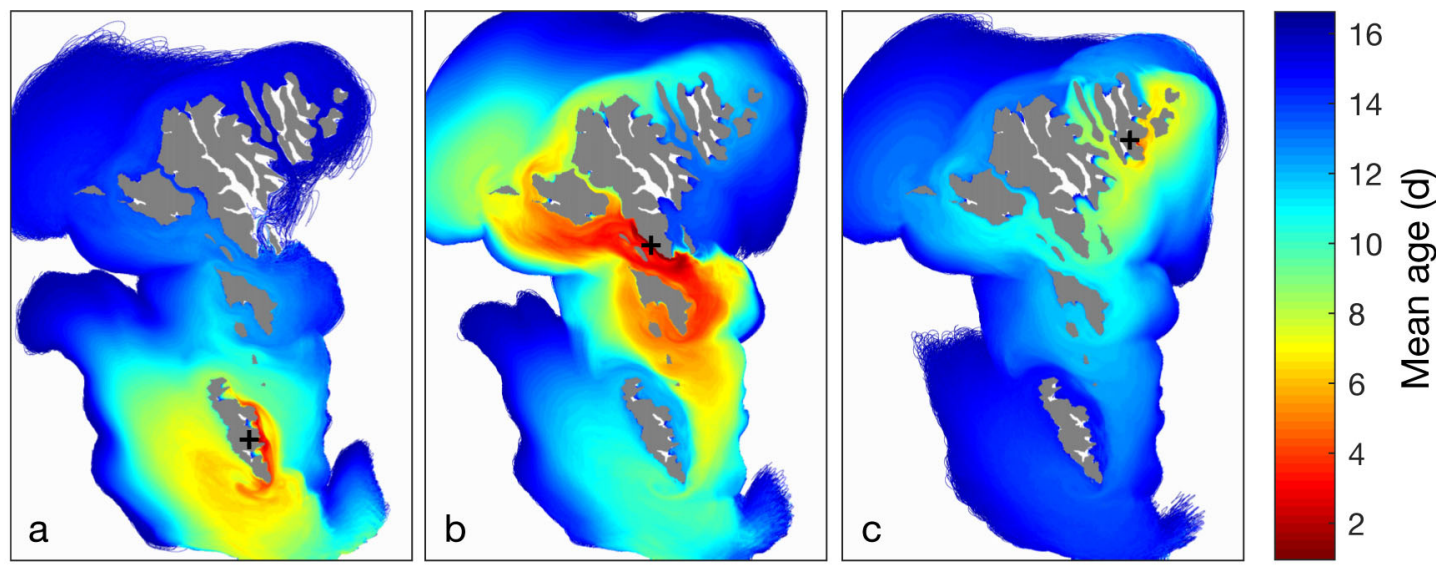

Fig. 4. Mean age of particles in every grid cell over the $2000 \mathrm{~h}$ simulation period. Every hour, 900 particles are released from Farms (a) 2, (b) 5, and (c) 21 (black crosses). White: no particles registered

Particles disperse rapidly from Farm 5 (Fig. 4b), which is located in the energetic strait on the west side of the largest island in the center. In contrast, the particle dispersion from the other 2 farm sites (Fig. $4 \mathrm{a}, \mathrm{c}$ ) is slow during the first few days, as seen by the limited dispersal area of the youngest particles (red). However, once particles escape their initial fjord, they enter what might be called a 'dispersion highway' that goes clockwise around the Faroe Islands. Here, they quickly disperse around the archipelago. These results illustrate that larvae are capable of traveling to almost any location around the Faroe Islands, some more likely than others, within their approximately 2 wk lifespan, provided that they manage to escape their release area. Further, the clockwise residual current also implies that only a few particles are lost from the system.

The maximum Euclidean distance traveled by a particle varies greatly between farms. Particles can easily travel more than $20 \mathrm{~km}$ during the nauplii phase (3.7 d in Faroese summer conditions, Fig. 5a). In 3 farms, including Farm 5 (dashed line with cross), over half of the particles travel over $40 \mathrm{~km}$. On the other hand, particles older than $3.7 \mathrm{~d}$ generally travel, not surprisingly, significantly longer distances than their nauplii counterparts (Fig. 5b). Over $50 \%$ of the particles from most farms travel over $50 \mathrm{~km}$. In several farms, including Farms 5 and 21, approximately $10 \%$ of the particles travel at least $80 \mathrm{~km}$. It should be noted that these particles are not weighted with mortality.

The relative distribution of nauplii and copepodid particles in each $100 \times 100 \mathrm{~m}$ grid cell over the whole simulation period, including mortality, is shown with a heat map (Fig. 6). Here, particles are recorded at every time step and weighted with survival probabil- ity. Particles released from several farms (10-11 and 22-23) have a very limited dispersion range both in the nauplii and copepodid stage. On the other hand, particles released from farms in more exposed areas, such as Farms 5 and 9, have relativity low densities at their initial release sites, indicating quick dispersion away from these areas after release. There are no clear 'cold' spots, i.e. areas with a relatively low density of copepodids, in the coastal regions. The exception is some of the fjords with little tidal influence, where estuarine circulation, which is neglected in the present simulation, must be expected to dominate the dispersion (Fig. 6b). The highest density is found around the northern group of islands, which is also where the majority of the farms are located.

\section{Connectivity}

The proportion and mean age of infectious salmon lice larvae that disperse between Faroese salmon farms is summarized in 3 connectivity matrices (Fig. 7). These reveal a generally high connection between farms although the range of connectivity is quite diverse. The diagonal line indicates the degree of self-infection and is dependent on the degree of exposure in the area. Farms 5, 9, and 13, which are located in tidally exposed areas (Fig. 3), are clearly not self-infectious (Fig. 7a,c). Farms 10, 11, 12, 20, 22, and 23 are close to $100 \%$ self-infectious and emit very few larvae to other farms, while also having a relatively (to the amount emitted) high infection rate from other farms.

The mean age in the highly self-infectious connections is close to $3.7 \mathrm{~d}$, the time when larvae become infectious, while the mean age for non-self-infectious 

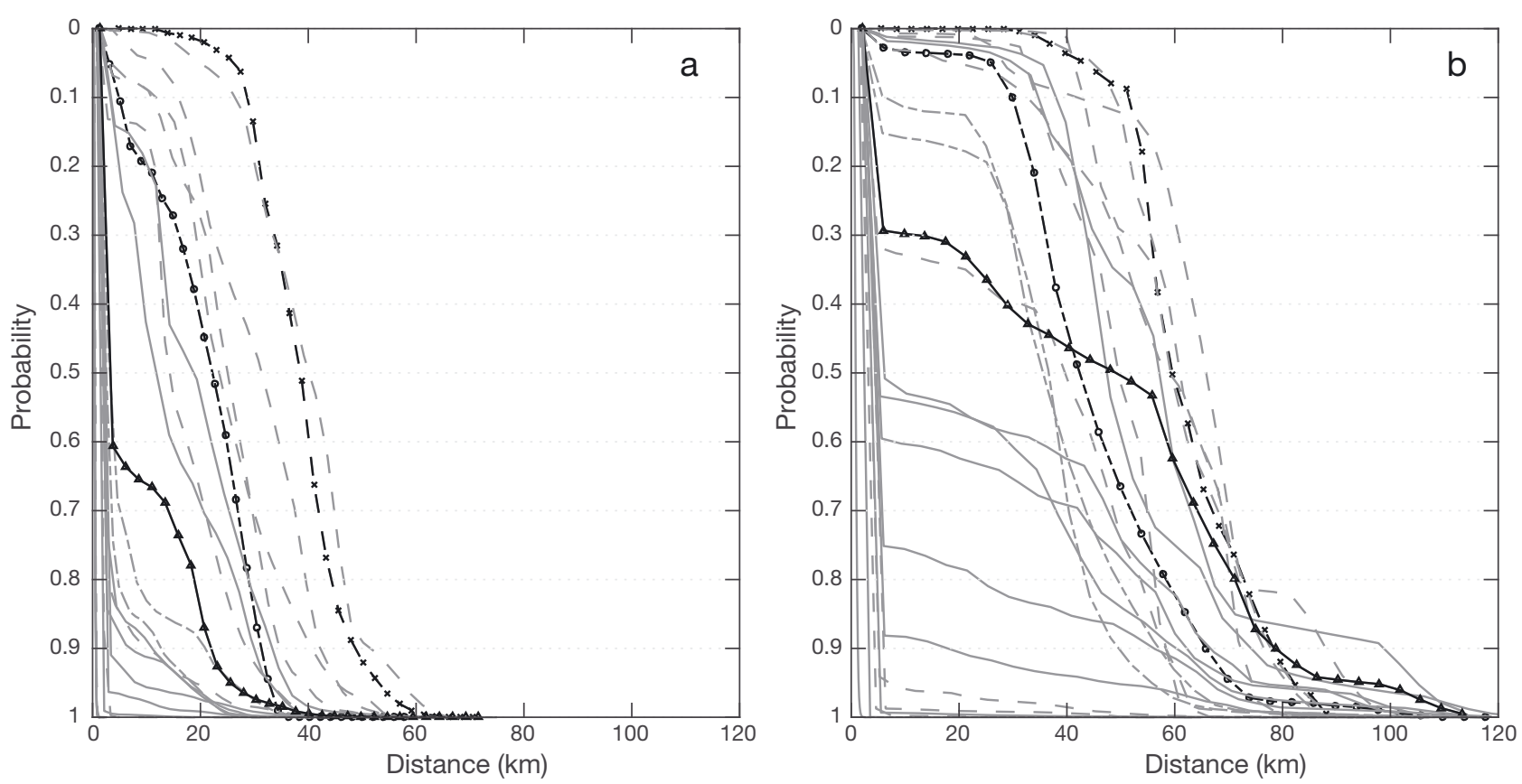

Fig. 5. The cumulative frequency of the maximum Euclidean distance attained by (a) nauplii and (b) copepodid particles released from all 24 sites. (Grey dash-dotted lines) Farms 1 to 3, (grey dashed lines) Farms 4 to 13, and (grey solid lines) Farms 14 to 24. As examples, 3 farms are highlighted: (dash-dotted line with circle) Farm 2, (dashed line with cross) Farm 5, and (solid line with triangle) Farm 21
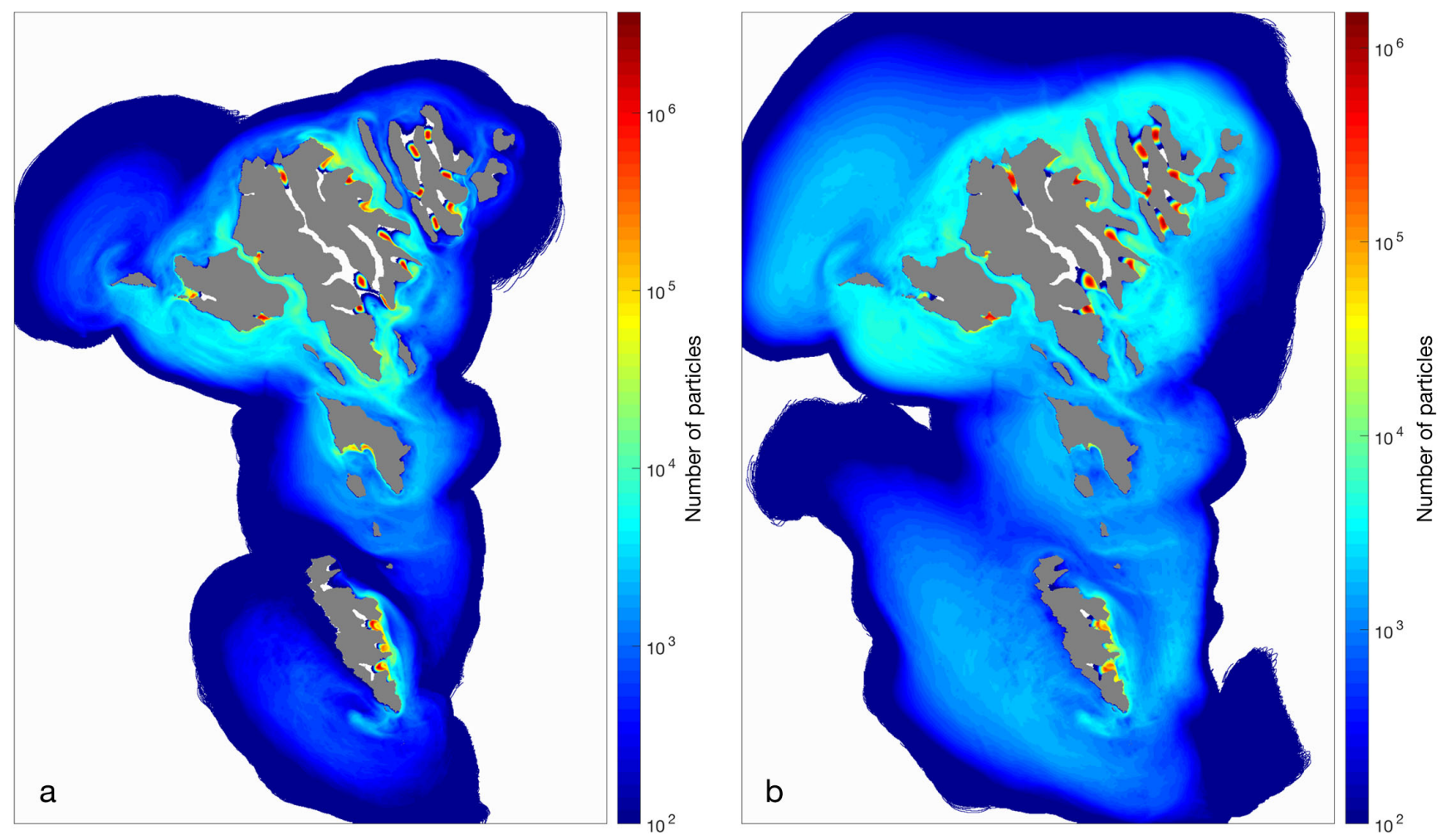

Fig. 6. Relative density distribution attained by particles released from all 24 farm sites, by recording the number of particles in each $100 \times 100 \mathrm{~m}$ grid cell every time step, including mortality, over the whole $2000 \mathrm{~h}$ simulation. (a) Nauplii and (b) copepodid particles. The color bar indicates number of particles on a logarithmic scale; white: no particles registered 


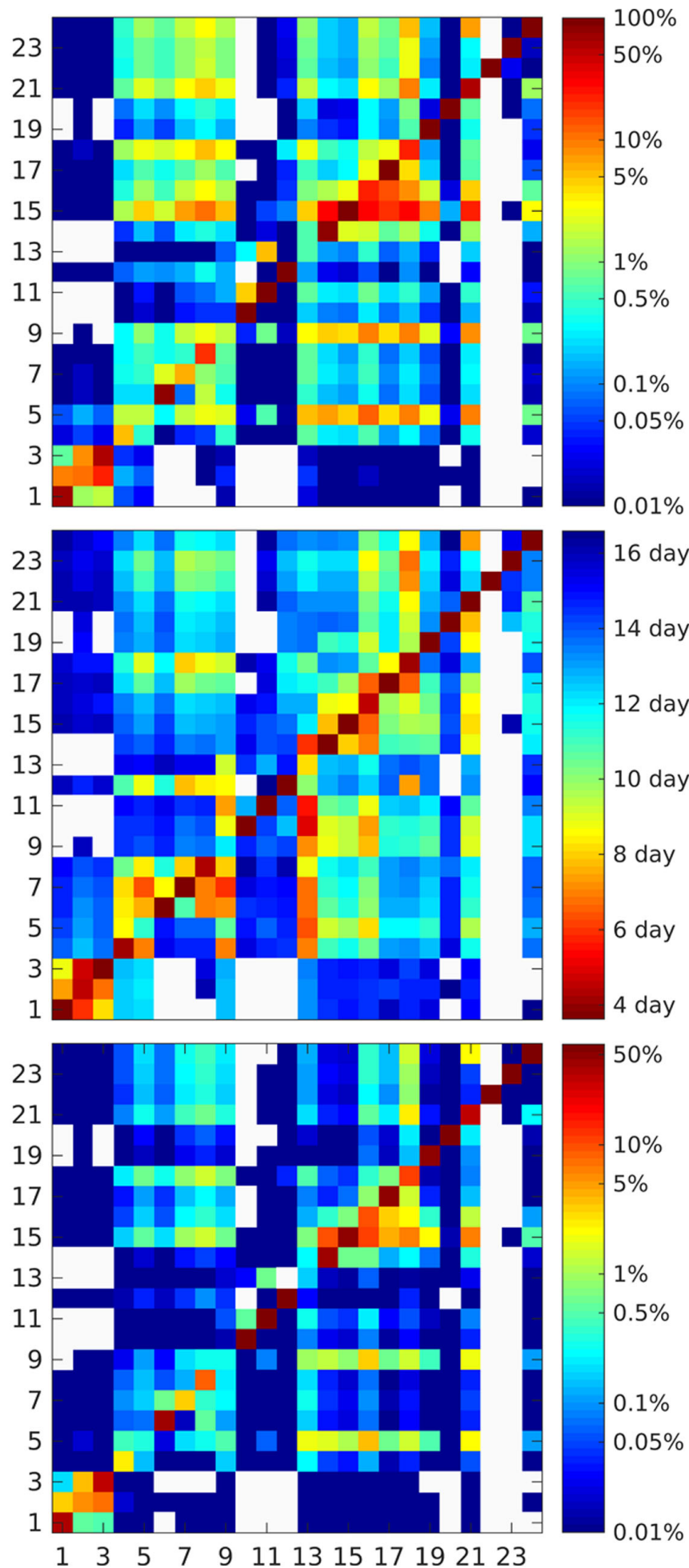

Fig. 7. (a) Percentage of unique infectious larvae released from one farm site entering any other farm site or its initial release site. (b) Mean age of the connections. (c) Connectivity including mortality. Emitting farms are on the $x$-axis and receiving farms on the $y$-axis. The color bar indicates the percentage in (a) and (c), scale is logarithmic. The color bar in (b) indicates the mean age in days. White indicates no signal farms is much higher, between 8 and $14 \mathrm{~d}$ (Fig. 7b). Larvae from Farm 5 infecting Farm 9 are very old (14 to $16 \mathrm{~d})$ and vice versa, even though they are very close geographically. This implies that the particles have traveled a long distance before entering the neighboring site. Interestingly, however, larvae from these farms infect nearby farms $(4,6,7$, and 8) with younger larvae.

Fig. $7 \mathrm{C}$ illustrates how infectious a connection is by accounting for mortality. Here the defined receiving area around Farm 15 receives over $10 \%$ of infectious particles from Farm 16, which is the strongest connection in the network. The matrices in Fig. 7 reveal at least 2 clusters of farms in the Faroe Islands. One includes Farms 1 to 3, which appear to be internally well connected with quite limited interaction with the other farms. With the exception of a few isolated farms, the rest of the network comprises a large connected cluster.

Farms are characterized as emitters, receivers, and/or isolated by the number of infectious larvae they emit and receive to and from other farms, excluding self-infection, expressed as \% of particles corresponding to the amount released from 1 farm site (Fig. 8). Farms 16, 18, 21, and 14 are the highest emitting, while Farm 15 is by far the highest receiving farm, followed by Farms 5, 9, and 2. Three farms are virtually isolated (10, 12, and 20, Fig. 8), as they are neither receivers nor emitters.

\section{DISCUSSION}

Our results demonstrate that Faroese salmon farms form a complex network with a wide range of connectivity strengths. The overall connectivity appears to be much higher than in other studies (Adams et al. 2012, 2015, Salama et al. 2013, in press, Johnsen et al. 2016, Samsing et al. 2017), although a direct comparison is problematic due to the differences in how connectivity is defined. Particles quickly disperse far and wide once outside a fjord and inside the 'dispersion highway', which runs clockwise around the Faroe Islands. For the most dynamic sites, there is a high probability that the particles reach a distance of more than $20 \mathrm{~km}$ from their origin, while in the most isolated fjords, there is a less than $10 \%$ probability that the particles travel further than $20 \mathrm{~km}$ before they become infectious. The maximum expected distance in the non-infectious stage is about $60 \mathrm{~km}$ for a few sites (Fig. 5a). Including the lifespan of the copepodid stage, there is a fairly high probability for the majority of the sites that the maximum distance is 

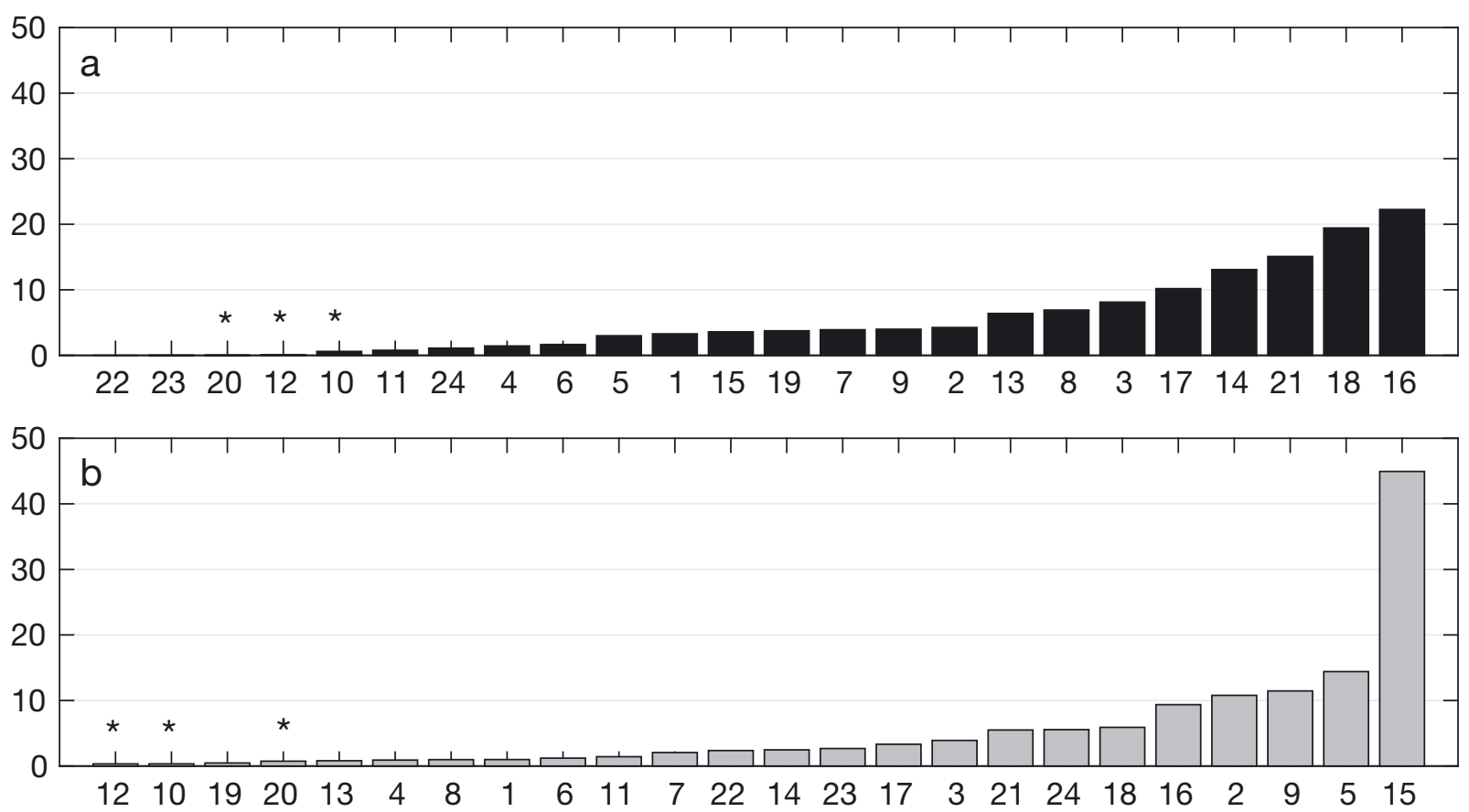

Fig. 8. Percentage of salmon lice which farms (a) emit and (b) receive to and from other farms accounting for mortality and excluding self-infection. * : the 3 highly isolated farms. Percentage is normalized with total amount of particles released from $1 \mathrm{farm}$

beyond $50 \mathrm{~km}$, and for some sites, there is a probability of up to $10 \%$ that they even reach beyond $80 \mathrm{~km}$ (Fig. 5b). These distances are comparable with the geographical size of the archipelago. Note that these distances are maximum Euclidean distances; the actual sea distance traveled may be considerable longer as they travel around the islands. Consequently, particles have the potential not only to infect the other farms, but also present a potential risk of delayed self-infection. The presented dispersion distances are comparable with maximum distances found along the Norwegian coast, but are considerably longer than the typical 20 to $40 \mathrm{~km}$ found in Norwegian fjords (Asplin et al. 2014) and the median distances of $6 \mathrm{~km}$ with maximum distances around $36 \mathrm{~km}$ in a Scottish loch (Salama \& Rabe 2013, Salama et al. 2016).

The self-infection in a number of farms is quite high, as seen by the low mean age and small dispersion range in these connections (Figs. $6 \& 7$ ). The high self-infection is partly caused by the low water fluxes in and out of these fjords, which may be underestimated due to the omission of the estuarine- and wind-driven circulation, and by the particles staying within the initial receiving area and therefore being recorded the moment they become infectious ( $3.7 \mathrm{~d})$.

Identifying critical nodes in the farm network provides highly valuable information for developing a management plan. We were able to identify farms as emitters, receivers, or isolated. The highest emitting farms $(16,18,21$, and 14, descending order; Fig. 8) are all located in the northern part of the Faroe Islands. They all emit the highest proportion of their infectious salmon lice particles to their close neighbor, Farm 15, which is the highest receiving farm (Fig. 3). Farm 16 emits over $10 \%$ of its infectious salmon lice to Farm 15, which must be considered a very strong connection. One reason Farm 15 is the highest receiver is that the defined receiving area is quite large as this fjord is relatively wide. In addition, the connection to the strait outside this fjord includes a tidally rectified eddy at the fjord mouth, which transports particles into the area. The connection decreases significantly if the receiving line at the fjord mouth is moved further into the fjord. Therefore, care should be taken in drawing bold conclusions about this relatively strong connection, but it still indicates that the infection risk in this fjord is considerable. The situation is quite different for the 2 following farms in the receiving rank list. They both have a modest receiving area, but have a large tidal through-flow resulting in a high particle flux from other farms.

The connectivity matrices suggest that the 3 farms at the southernmost islands (Farms 1 to 3 ) are largely separated from the other islands, but are internally well connected. The rest of the farm network seems 
to be 1 cluster with negligible contribution from the 3 isolated farms $(10,12$, and 20) and the 3 relatively isolated farms (11 and 22-23) (Fig. 8). These isolated farms are in the narrow strait between the 2 main islands and in fjords in the northeast group of islands, which all are characterized by weak tidal currents (Fig. 1). Likely, the dispersion within these areas is dominated by estuarine- and/or wind-driven circulation (Gaard et al. 2011), which is not included in the present model.

Recently, Patursson et al. (2017) assessed variations in salmon lice population dynamics in Faroese farms in relation to the physical exposure to the local circulation patterns and flushing with adjacent waters expressed through an exposure index, and found that up to $65 \%$ of the variations in the sea lice dynamics was related to the freshwater input and tides. In the fjords with Farms 20 and 22-23, they found a generally low exposure, of which 60 to $70 \%$ was explained by the freshwater runoff, and a generally higher exposure index for the fjord hosting Farm 10, where nearly $90 \%$ of the sea lice variance could be related to the freshwater runoff. A study conducted in Kaldbaksfjord (Farm 10, Fig. 3) indicated an average exchange rate of approximately $10 \mathrm{~d}$ (Gaard et al. 2011), in contrast to virtually no exchange found in our simulations. Including wind and freshwater forces will increase the interaction with the other farms in the northern cluster as well as the rest of the farm network. However, in calm and dry periods, when the tides are the primary forcing mechanism, these farms must be considered as isolated and highly self-infectious.

The connectivity in this study was measured as the number of infectious particles (older than $3.7 \mathrm{~d}$ ) released at one farm entering the defined receiving area of another farm or its own. Adams et al. (2012) took particles out of the simulation after the first connection. In many cases particles in our simulations did not leave their own receiving area before becoming infectious because we defined the whole fjord as a potential infection risk. This is evident when looking at the mean age in most of the self-infection connections (Fig. 7b). It would have been unpractical in our setup to take particles out of the simulation after 1 connection as we would then only have observed self-infection in most cases. Therefore, particles were allowed to continue in the simulation but they were only allowed to infect once in any given connection. One downside of this method is that relevant information is lost, such as the amount of time an infectious salmon louse spends in a farm area. Johnsen et al. (2016) and Samsing et al. (2017) partially solved this by letting salmon lice reinfect a farm site multiple times. Some studies include the biomass and/or salmon lice counts in the farm connectivity (Salama et al. in press, Samsing et al. 2017). This is especially relevant when studying specific time periods and verifying salmon lice counts, which, however, is not the case in our simulations. Here all farms release an equal amount of particles, which can represent any arbitrary uniform number of salmon lice. This provides the option to include number of salmon lice in a future expansion of the model when fish and salmon lice count data at farm level become available. As mentioned, the connectivity probabilities found in this study are high compared to other studies. This is in part due to the way we define our receiving area, but likely also due to salmon lice having a very high dispersion range in the Faroe Islands, in contrast to other areas.

Averaged over several spring-neap tide cycles, the only parameters that can change the connectivity are the length of the planktonic phases and the mortality. This study assumed typical Faroese summer conditions. We also ran some simulations in winter conditions, under which the planktonic phases become longer, and observed differences in the connectivity, although the overall connectivity pattern appeared very similar to that simulated under summer conditions.

The Faroe Islands are notoriously windy, especially in the winter months. The dominating wind direction is southwest, while the less frequent direction is east, although the wind direction and strength is highly variable due to the geographical location of the Faroe Islands in the path of the low pressures crossing the Atlantic (Cappelen \& Laursen 1998, Larsen et al. 2008). The wind strength and direction in the fjords and straits are highly influenced by the surrounding mountains, but no meteorological data with sufficiently high spatial resolution is currently available for the area. Wind most likely affects the dispersion dynamics, especially on short time scales, forcing salmon lice larvae out of or into a fjord, while outside the fjords, wind affects the drifting path. However, due to the variability in the wind forcing, it is likely that the overall distribution will be spread out even more than that obtained here from the underlying tidal forcing only, but this still remains to be investigated.

The results presented have many implications which can benefit the Faroese aquaculture industry, where there is currently no coordinated treatment management plan based on the underlying hydrographic connectivity between the sites. As men- 
tioned, all farms are weighted equally, as we assumed a linear process. The connectivity matrices may therefore be seen as a background or underlying connectivity providing options to include the individual sea lice pressure of the farms when this information is released from confidentiality.

Our results clearly demonstrate that a holistic treatment plan should be developed, as salmon farms are not isolated but are connected to each other. Intuitively, we would strictly manage the farms that are characterized as emitters to prevent unnecessary external infection pressure on other farms, e.g. Farms 16, 18, and 21 (if all farms contribute equally). On the contrary, Adams et al. (2015) combined connectivity estimates with a salmon lice population dynamic model developed by Revie et al. (2005) and found that management was most effective when targeting the highest receiving or influx farms, which is somewhat counter-intuitive. This finding suggests the need to include population dynamics, specifically to examine the network response to different treatment strategies.

In addition to treatment strategies, the approach described here can also aid in the planning of farm locations. For instance, salmon farmers can decide to place their farms further out or into the fjord. The trend in the Faroe Islands in recent years has been to place farms further out in the fjord to obtain better growth conditions due to higher water exchange, less local bed load, and less sea lice self infection. However, placing farms further out, as recommended by, e.g. Samsing et al. (2015), increases the connectivity between farms. In this way, the benefit to the individual farm enlarges the challenge for the entire farm network. Also the placement of potential new farm sites is problematic as there are no obvious salmon lice 'cold spots' close to the Faroese coast (Fig. 6), emphasizing the need for a holistic management approach.

\section{CONCLUSIONS}

During the last decade, there has been a gradual increase in the use of numerical models to study the dispersion of Lepeophtheirus salmonis in all leading Atlantic salmon-producing countries, and they are now at a state where fairly realistic results can be obtained (Stucchi et al. 2011, Salama \& Rabe 2013, Asplin et al. 2014, Johnsen et al. 2016, Samsing et al. 2017, Salama et al. in press). This study presents the first model which can, to a certain degree, realistically simulate the mean dispersion patterns in an archipelago with a circulation dominated by tidal currents. Due to their highly dominating influence on water currents on the Faroe shelf, the tidal currents and the residual current are the main factors responsible for the connectivity between farms sites, as well as acting as a retention mechanism for the resident sea lice population.

We acknowledge that wind and freshwater forcing, which are not included in the present study, will influence the dispersion dynamics, especially on shorter time scales in the more sheltered fjords. However, on longer time scales the highly dominating Faroese tidal forcing will reflect the mean dispersion pattern, enabling valuable insight into the background connection between farms in the Faroe Islands.

In summary, the basis for the creation of a robust biophysical model has been developed, which can help to find an optimal treatment and management plan for the Faroese aquaculture industry.

Acknowledgements. This study was financially supported by Danmarks Innovationsfond (Grant No. 5189-00032A) and by Granskingarráðið - Research Council Faroe Islands (Grant No. 0450). We also appreciate the valuable comments from Dr. Nabeil Salama and 2 anonymous reviewers on an earlier version of the manuscript.

\section{LITERATURE CITED}

á Norði G, Simonsen K, Danielsen E, Eliasen K and others (2015) Abundance and distribution of planktonic Lepeophtheirus salmonis and Caligus elongatus in a fish farming region in the Faroe Islands. Aquacult Environ Interact 7:15-27

Aaen SM, Helgesen KO, Bakke MJ, Kaur K, Horsberg TE (2015) Drug resistance in sea lice: a threat to salmonid aquaculture. Trends Parasitol 31:72-81

Adams T, Black K, MacIntyre C, MacIntyre I, Dean R (2012) Connectivity modelling and network analysis of sea lice infection in Loch Fyne, west coast of Scotland. Aquacult Environ Interact 3:51-63

Adams TP, Proud R, Black KD (2015) Connected networks of sea lice populations: dynamics and implications for control. Aquacult Environ Interact 6:273-284

Amundrud TL, Murray AG (2009) Modelling sea lice dispersion under varying environmental forcing in a Scottish sea loch. J Fish Dis 32:27-44

Asplin L, Johnsen IA, Sandvik AD, Albretsen J, Sundfjord V, Aure J, Boxaspen KK (2014) Dispersion of salmon lice in the Hardangerfjord. Mar Biol Res 10:216-225

Boxaspen K (2006) A review of the biology and genetics of sea lice. ICES J Mar Sci 63:1304-1316

Brickman D, Ådlandsvik B, Thygesen U, Parada C, Rose K, Hermann A, Edwards K (2009) Particle tracking. In: North EW, Gallego A, Petitgas P (eds) Manual of recommended practices for modelling physical-biological interactions in fish early life. ICES Cooperative Research Reports No. 295, Copenhagen, p 9-19

Cappelen J, Laursen EV (1998) The climate of the Faroe 
Islands: with climatological standard normals, 1961-90. Danish Meteorological Institute Technical Report 98-14, Copenhagen

Costello MJ (2009) The global economic cost of sea lice to the salmonid farming industry. J Fish Dis 32:115-118

Egbert GD, Bennett AF, Foreman MG (1994) TOPEX/ POSEIDON tides estimated using a global inverse model. J Geophys Res Oceans 99:24821-24852

FAO (Food and Agriculture Organization of the United Nations) (2017) Global aquaculture production 19502015. Fisheries and aquaculture department, FAO, Rome. www.fao.org/fishery/statistics/global-aquacultureproduction/query/en

Ford JS, Myers RA (2008) A global assessment of salmon aquaculture impacts on wild salmonids. PLOS Biol 6:e33

Gaard E, á Norði G, Simonsen K (2011) Environmental effects on phytoplankton production in a Northeast Atlantic fjord, Faroe Islands. J Plankton Res 33:947-959

Gillibrand PA, Willis KJ (2007) Dispersal of sea louse larvae from salmon farms: modelling the influence of environmental conditions and larval behaviour. Aquat Biol 1: 63-75

Gravil H (1996) Studies on the biology and ecology of the free swimming larval stages of Lepeophtheirus salmonis (Krøyer, 1838) and Caligus elongatus Nordmann, 1832 (Copepoda: Caligidae). PhD thesis, University of Stirling

Johnsen IA, Fiksen Ø, Sandvik AD, Asplin L (2014) Vertical salmon lice behaviour as a response to environmental conditions and its influence on regional dispersion in a fjord system. Aquacult Environ Interact 5:127-141

* Johnsen IA, Asplin LC, Sandvik AD, Serra-Llinares RM (2016) Salmon lice dispersion in a northern Norwegian fjord system and the impact of vertical movements. Aquacult Environ Interact 8:99-116

Johnson S, Albright L (1991) Development, growth, and survival of Lepeophtheirus salmonis (Copepoda: Caligidae) under laboratory conditions. J Mar Biol Assoc UK 71: 425-436

Kabata Z (1979) Parasitic Copepoda of British fishes. Ray Society, London

* Larsen KMH, Hansen B, Svendsen H (2008) Faroe shelf water. Cont Shelf Res 28:1754-1768

Murray AG (2011) A simple model to assess selection for treatment-resistant sea lice. Ecol Modell 222:1854-1862

Patursson EJ, Simonsen K, Visser AW, Patursson Ø (2017) Effect of exposure on salmon lice Lepeophtheirus salmonis population dynamics in Faroese salmon farms. Aquacult Environ Interact 9:33-43

Pawlowicz R, Beardsley B, Lentz S (2002) Classical tidal harmonic analysis including error estimates in MATLAB using T_TIDE. Comput Geosci 28:929-937

Pike AW, Wadsworth SL (1999) Sealice on salmonids: their biology and control. Adv Parasitol 44:233-337

* Revie CW, Robbins C, Gettinby G, Kelly L, Treasurer J (2005) A mathematical model of the growth of sea lice, Lepeophtheirus salmonis, populations on farmed Atlantic salmon, Salmo salar 1., in Scotland and its use in the

Editorial responsibility: Bengt Finstad,

Trondheim, Norway assessment of treatment strategies. J Fish Dis 28:603-613

* Salama NKG, Rabe B (2013) Developing models for investigating the environmental transmission of diseasecausing agents within open-cage salmon aquaculture. Aquacult Environ Interact 4:91-115

Salama NKG, Collins CM, Fraser JG, Dunn J, Pert CC, Murray AG, Rabe B (2013) Development and assessment of a biophysical dispersal model for sea lice. J Fish Dis 36: 323-337

Salama NKG, Murray AG, Rabe B (2016) Simulated environmental transport distances of Lepeophtheirus salmonis in Loch Linnhe, Scotland, for informing aquaculture area management structures. J Fish Dis 39:419-428

Salama NKG, Dale AC, Ivanov VV, Cook PF, Pert CC, Collins CM, Rabe B (in press) Using biological-physical modelling for informing sea lice dispersal in Loch Linnhe, Scotland. J Fish Dis, doi:10.1111/jfd.12693

Samsing F, Solstorm D, Oppedal F, Solstorm F, Dempster T (2015) Gone with the flow: current velocities mediate parasitic infestation of an aquatic host. Int J Parasitol 45: 559-565

Samsing F, Oppedal F, Dalvin S, Johnsen I, Vågseth T, Dempster T (2016) Salmon lice (Lepeophtheirus salmonis) development times, body size and reproductive outputs follow universal models of temperature dependence. Can J Fish Aquat Sci 73:1841-1851

Samsing F, Johnsen I, Dempster T, Oppedal F, Treml EA (2017) Network analysis reveals strong seasonality in the dispersal of a marine parasite and identifies areas for coordinated management. Landsc Ecol 32:1953-1967

SFI (Statistics Faroe Islands) (2017) Statbank. www.hagstova. fo/en/statbank

Shchepetkin AF, McWilliams JC (2005) The regional oceanic modeling system (ROMS): a split-explicit, freesurface, topography-following-coordinate oceanic model. Ocean Model 9:347-404

* Shinn AP, Pratoomyot J, Bron JE, Paladini G, Brooker EE, Brooker AJ (2015) Economic costs of protistan and metazoan parasites to global mariculture. Parasitology 142: 196-270

Simonsen K, Niclasen BÁ (2011) On the energy potential in the tidal streams on the Faroe Shelf. Technical Report, Faculty of Science and Technology, University of the Faroe Islands, Tórshavn

* Stien A, Bjørn PA, Heuch PA, Elston DA (2005) Population dynamics of salmon lice Lepeophtheirus salmonis on Atlantic salmon and sea trout. Mar Ecol Prog Ser 290: 263-275

Stucchi DJ, Guo M, Foreman MG, Czajko P, Galbraith M, Mackas DL, Gillibrand PA (2011) Modelling sea lice production and concentrations in the Broughton Archipelago, British Columbia. In: Jones S, Beamish R (eds) Salmon lice: an integrated approach to understanding parasite abundance and distribution. Wiley-Blackwell, Oxford, p 117-150

*Visser AW (1997) Using random walk models to simulate the vertical distribution of particles in a turbulent water column. Mar Ecol Prog Ser 158:275-281

Submitted: June 8, 2017; Accepted: November 22, 2017 Proofs received from author(s): January 28, 2018 